\title{
Work Values, Job Involvement, and Organizational Commitment in Taiwanese Nurses
}

\author{
Chin-Chih Ho ${ }^{1}$, Brian Oldenburg ${ }^{2}$, Gary Day ${ }^{3}$, Jing Sun ${ }^{4, *}$ \\ ${ }^{1}$ Department of Health Administration, Central Taiwan University of Science and Technology, Taiwan \\ ${ }^{2}$ Department of Epidemiology and Preventive Medicine, Monash University, Australia \\ ${ }^{3}$ School of Public Health, Griffith University, Australia \\ ${ }^{4}$ School of Public Health and Griffith Health Institute, Griffith University, Australia
}

\begin{abstract}
Employees' belief in the traditional work ethics of hard work and diligence as virtues in their own right has significantly declined in recent times in Taiwan. Job involvement as a mediator of the influence of work values on organizational commitment remains unclear, and needs to be explored in a non-western work context. In addition, the degree of organizational commitment has not been shown to be related to the actual amount of nursing work or labor intensity required in any nursing care environment. This study investigates the relationship between work values, job involvement and organizational commitment in a sample of 1047 Taiwanese nurses from Taiwan. The study utilizes a cross-sectional survey design. The sample consisted of Registered Nurses $(\mathrm{RNs})(\mathrm{N}=1,047)$ recruited from a convenience sample in nine regional and teaching hospitals in Taiwan. Results showed that work values were positively related to job involvement and organizational commitment, and job involvement is positively related to organizational commitment. Subsequent analyses revealed that job involvement could play an important role in mediation, and that establishing a higher level of job involvement may be more important than focusing only on organizational commitment. This study has implications for organizations attempting to enhance organizational commitment through increased job involvement. It is anticipated that by improving these various factors, the turnover and absenteeism will be reduced and the organizations become more effective and productive.
\end{abstract}

Keywords Work Values, Job Involvement, Organizational Commitment, Taiwanese Nurses

\section{Introduction}

The macro-economic environment in the Taiwanese healthcare system has changed over time to address issues such as cost containment, the over-supply of nurses and an inflexible career system. As a result, average turnover rate of new staff nurses in Taiwan's hospitals has varied between 22-40 per cent in recent years (8). Employees' belief in the traditional work ethics of hard work and diligence as virtues in their own right has significantly declined in recent times in Taiwan (32). It is likely employees' perceptions of work and work organizations have changed. Unless organizations are able to meet a range of employee's needs, employees cannot be expected to be highly involved in their jobs or organizations (18).

It is important for managers of healthcare organizations to assess the impact of these various influences on the way their employees view their jobs, and address these challenges to the thinking, recruitment, motivation, and retention of their productive staff. Lack of any of these elements

* Corresponding author:

j.sun@griffith.edu.au (Jing Sun)

Published online at http://journal.sapub.org/ijpbs

Copyright (C) 2012 Scientific \& Academic Publishing. All Rights Reserved of work commitment may account for employee absenteeism, turnover, reduced effort, and job dissatisfaction (18). In order to compete successfully in the healthcare environment, and attract and retain the most qualified and experienced nurses, it is important for organizations to implement strategies that increase job involvement and organizational commitment (5). Within the literature, the role of job involvement in particular has not been adequately addressed. More specifically, job involvement as a mediator on the influence of work values on organizational commitment remains unclear, as most studies focused on western cultural context. In addition, the degree of organizational commitment has yet to be shown to be related to the actual amount of nursing work or labor intensity required in any nursing care environment (30).

Work values are a particularly important work commitment construct, as they play a key role in influencing an employee's affective responses in the workplace. Work values have been commonly viewed as a personality variable $(12,16,20)$, a strong antecedent of all three work attitudes (e.g. job involvement, organizational commitment, and career salience) (26), and a relatively unchanged feature over an individual's life course (17). Morrow and McElroy (19) point out that work values are the key to job involvement and other emotional reactions, and uncovered direct 
evidence that work values are positively related to job involvement in the work force. Randall and Cote (23) also found that individuals holding strong work values were more involved in their jobs. Organizational commitment is a different work attitude from job involvement, however a number of studies have highlighted the connection between organizational commitment and job involvement $(17,20,21)$. Job involvement, as a function of early socialization experiences (14), is more stable than organizational commitment (4). Moreover, both variables are thought to influence some work-related behavior independently (24), and result in a significant interactive relationship (4).

This study focuses on three specific determinants of work commitment: work values, job involvement and organizational commitment. The framework for this study is based on a modified version of Randall and Cote's Model (23) and Randall and Cote's Revised Model (9). These models were chosen because the various determinants of work commitment have not been the focus of comparative studies in Taiwan, and as such are not yet fully understood (23). The path model in Figure 1 is used to depict the relationships among the variables investigated by the current study. The model describes the effect of work values and job involvement on organizational commitment. It is hypothesized that individuals who are highly committed to the importance of work may develop a strong loyalty to the organization where they work. It is also hypothesized that having work values results in increased job involvement, which would subsequently lead to increased organizational commitment.

\section{Method}

\subsection{Sample and Procedure}

The target population for this study consisted of RNs who worked in regional teaching hospitals in Taiwan. The samples were recruited via convenience sampling, with nine hospitals in Taiwan selected to participate in the study. Moreover, participants were required to match the following inclusion criteria: (a) be an RN; (b) be employed full-time or part-time, and have completed at least three months of service (to ensure that participants have at least some familiarity with the job and organization); and (c) be willing to participate. Subjects who met the inclusion criteria were invited to participate in the study, and asked to fill in the questionnaire. The head nurse of the unit of selected hospitals distributed the questionnaires, and each $\mathrm{RN}$ from the selected nursing units was provided with a questionnaire package. This included a cover letter explaining the purpose of the study, details of confidentiality, and detailed instructions about completing the questionnaire. At the end of the data collection period, the researcher collected lodgement boxes containing the completed questionnaires from each of the selected hospitals. Of the 1300 questionnaires distributed, 1053 were completed and returned, a response rate of 81 per cent.
Table 1 presents the socio-demographic profile of the sample. Respondents were predominantly females (99.0 percent). The mean age was $30.52(\mathrm{SD}=6.49)$ with approximately 73 percent of respondents having a diploma-level education. The majority of respondents (43.6 percent) indicated their income was between $A \$ 15,001$ and A $\$ 20,000$. More than half (57.5 percent) of the respondents in the study were registered professional nurses, close to one-third (31.9 percent) of respondents were registered nurses, 8.5 percent were head nurses, and 1.0 percent were supervisors. Six questionnaires were excluded from final analysis due to the low number of male respondents, leaving a sample of 1047.

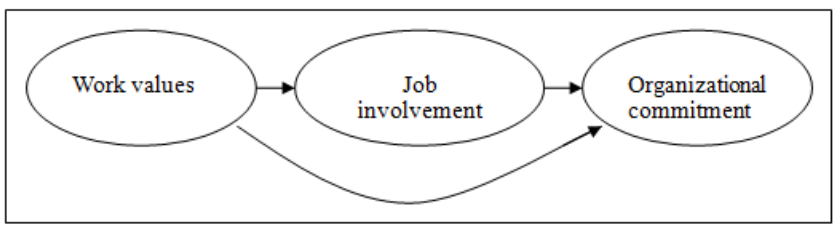

Figure 1. Theoretical Framework

Table 1. Socio-demographic Profile $(\mathrm{N}=1053)$

\begin{tabular}{|c|c|c|c|c|c|}
\hline Variable & $\mathrm{n}^{*}$ & $\begin{array}{c}\text { Valid } \\
\%\end{array}$ & Variable & $\mathrm{n}^{*}$ & $\begin{array}{c}\text { Valid } \\
\%\end{array}$ \\
\hline Gender & & & Personal income & & \\
\hline Female & 1043 & 99.0 & $<\mathrm{A} \$ 15,000$ & 174 & 16.5 \\
\hline \multirow[t]{4}{*}{ Male } & 6 & 0.6 & $\mathrm{~A} \$ 15,001-20,000$ & 459 & 43.6 \\
\hline & & & $\mathrm{A} \$ 20,001-25,000$ & 224 & 21.3 \\
\hline & & & $\mathrm{A} \$ 25,001-30,000$ & 84 & 8.0 \\
\hline & & & $>\$ 30,001$ & 92 & 8.7 \\
\hline $\begin{array}{c}\text { Education } \\
\text { status }\end{array}$ & & & Position: & & \\
\hline $\begin{array}{c}\text { Secondary } \\
\text { school in } \\
\text { nursing }\end{array}$ & 43 & 4.1 & $\begin{array}{l}\text { Registered pro- } \\
\text { fessional nurse }\end{array}$ & 336 & 31.9 \\
\hline Diploma & 767 & 72.8 & Registered nurse & 605 & 57.5 \\
\hline Bachelor & 233 & 22.1 & Head nurse & 89 & 8.5 \\
\hline Masters & 7 & 0.7 & Supervisor & 11 & 1.0 \\
\hline \multicolumn{6}{|l|}{ Age } \\
\hline $\begin{array}{l}\text { Less than } \\
25 \text { years }\end{array}$ & 196 & 18.6 & & & \\
\hline $26-30$ & 477 & 45.3 & & & \\
\hline $31-35$ & 181 & 17.2 & & & \\
\hline $36-40$ & 86 & 8.2 & & & \\
\hline Over 41 & 90 & 8.5 & & & \\
\hline \multicolumn{6}{|l|}{$\begin{array}{c}\text { Mean }= \\
30.52\end{array}$} \\
\hline $\mathrm{SD}=6.49$ & & & & & \\
\hline & 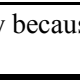 & & $\begin{array}{l}\text { deletion of mis } \\
\text { cedure }\end{array}$ & A & \\
\hline
\end{tabular}

\subsection{Instrumentation}

Work values were measured using a Mandarin translation of a modified indigenous version (49 items) of Super's (28) Work Values Inventory (WVI) (36). There were a total of 49 items with seven-factor structures for measuring the level of work values, rather than using only the four items of Protestant Work Ethic (PWE) (23). A response to each statement was made on a five-point Likert-type scale ranging from one, not important to five, very important. A higher score reflects 
a higher placing importance on values of work. Job involvement is defined in the current study as the psychological importance of one's job, and was measured with the 10-item Job Involvement Questionnaire (JIQ) (14). Responses were scored on a five-point Likert scale (ranging from one, strongly disagree to five, strongly agree). The 10 items were summed to provide a total involvement score, two of which are negatively phrased and hence reverse scored. High scores reflect a higher level of job involvement. Organizational commitment is defined as the relative strength of an employee's identification with, and involvement in, a particular organization. The Organizational Commitment Questionnaire (OCQ) used to test organizational commitment was based on a translation of the Mowday et al. (21) scale into Mandarin by Wu and Yang (34). This five-point scale used a 15 -item Likert scale with three-factor structures, six items of which are negatively phrased and reverse scored - the higher the score, the greater the employee's commitment to the organization.

This study is the first in which the three instruments were used together in the Taiwanese nursing field. Validity of these measurement scales has been demonstrated in Taiwan in the fields of education and business $(15,33,35)$, but there is no published evidence about the JIQ's construct validity in Taiwan (8). Therefore, as a preliminary step in analysis of the current research data, the validity and reliability of the measures used was established. The WVI and OCQ were analyzed using Confirmatory Factor Analysis (CFA) and the JIQ by using Exploratory Factor Analysis (EFA). CFA and EFA are two statistical approaches that can be used to examine the internal reliability of a measure. CFA was used because it is a powerful tool for testing an existing theory, allowing the researcher to test and systematically compare specified a priori models. This analysis is considered more appropriate if prior hypotheses exist based on theory or previous analysis (10). EFA was undertaken for the JIQ, as this analysis does not have well specified priority restrictions on the structure of the model (25). Both statistical approaches can provide strong evidence for the internal validity and reliability of a measure.

CFAs using LISREL 8.71 were employed to confirm the factor structure of work values and organizational commitment constructs. CFA, with maximum likelihood (ML) estimation, was conducted to specify correlated measurement error and to estimate the true correlations (factor loadings) between the underlying constructs (29). There are six common approaches reported in the literature to analyzing model fit, including: Chi-square statistics $\left(\chi^{2}\right)$, chi-square to degrees of freedom ratio $\left(\chi^{2} / \mathrm{df}\right)$, the Normed Fit Index (NFI)(3), the Comparative Fit Index (CFI)(2), the Goodness of Fit Index (GFI) and the Root-Mean Square Error of Approximation (RMSEA). In practice, a non-significant chi-square test is available, but chi-square is sensitive to sample sizes (29). If the chi-square to degrees of freedom ratio $\left(\chi^{2} / \mathrm{df}\right)$ is below three, this is generally accepted as a moderate fit. According to Hertzog (11), a model can still be considered useful even when the likelihood ratio chi-square test is statistically significant. The NFI, CFI and GFI range between zero and one, with values higher than 0.9 generally accepted as representing a reasonable model fit. Values of 0.05 or less indicate a good fit, and a value ranging from 0.05 to 0.1 is indicative of reasonable fit for the RMSEA index (6).

As shown in Table 2, the results of the CFA for WVI, these fit indices (NFI $=0.97, \mathrm{CFI}=0.98, \mathrm{GFI}=0.73$, and RMSEA $=0.084)$ indicate a reasonable model fit. The seven-factor structure hypothesized to underlie the work values scale was confirmed. The results of CFA for OCQ revealed that NFI $=0.97, \mathrm{CFI}=0.97, \mathrm{GFI}=0.81$ and RMSEA $=0.078$, thus indicating a reasonable model fit. The three-factor structure hypothesized to underlie the organizational commitment scale was confirmed.

Table 2. Goodness of Fit (GOF) Statistics for WVI and OCQ

\begin{tabular}{|c|c|c|c|c|c|c|c|}
\hline & $\mathrm{X} 2$ & df & $\mathrm{X} 2 / \mathrm{df}$ & NFI & CFI & GFI & RMSEA \\
\hline WVI & $7802.86 * *$ & 1106 & 7.06 & .97 & .98 & .73 & .084 \\
\hline OCQ & $620.29 * *$ & 87 & 7.13 & .97 & .97 & .81 & .078 \\
\hline
\end{tabular}

EFA using a Principal Components Analysis (PCA) was conducted to investigate the construct of job involvement (with a varimax rotation) using the JIQ. The significant Bartlett's Test of Sphericity $(\chi 2=4453.45, p<.01)(1)$ and Kaiser-Meyer-Olkin (KMO) test (0.88) (13) indicated that the data were suitable for structure detection. In the first phase of PCA analysis, three factors were extracted. Factor three contained only one item (item two) and was dropped. In the second phase of analysis, it was found that the best solution was a two-factor solution. Inspection of the corrected item-total correlation revealed that the coefficient for item seven was below 0.3 (-.084). Corrected item-total correlations should be considered the minimum acceptable evidence of construct validity (22). They are important because they give researchers an indication of the extent to which each item contributes to a scale or subscale. Item seven was therefore dropped. This meant the items were loaded on two factors, accounted for 65.83 percent of total variance, and had a Cronbach's $\alpha$ of .89 .

Kanungo (14) had indicated that his 10-item JIQ was a uni-dimensional construct. However, this study revealed that job involvement involves at least two factors in the Taiwanese setting. It is possible that individual items are interpreted differently by persons in different cultures $(12,31)$. In addition, although Kanungo's (14) JIQ has previously been used in other Taiwanese industrial samples (8), it had not been implemented in a nursing sample. Therefore, professional differences may also influence the study findings.

\section{Results}

The data from this study was analyzed using a range of statistical techniques, including: means, standard deviations and regression analysis. The means and standard deviations for the variables of work values, job involvement and or- 
ganizational commitment are shown in Table 3 .

Work values, the mean score of $4.09(S D=.54)$ implies that many nurses scored the items highly. The nurses were not very different in their perceptions of work values. The WVI was divided into subscales, measuring terminal or instrumental aspects of work. "Terminal values" included three work values. There were high ratings for "self-growth", with a mean score of 4.05 , but low ratings for "self-esteem", with a mean score of 3.92. "Instrumental values" measured four work values, with the highest ratings for "social interaction considerations", with a mean score of 4.29 , "security and economic considerations", with a mean of 4.18 , "stability and freedom from anxiety considerations", with a mean of 4.15. The "instrumental value", with the lowest ratings was "recreation, health and transport considerations", with a mean score of 4.09 .

Table 3. Mean and Standard Deviation for Scales and Subscales and Ranking for Major Variables ( $=1047)$

\begin{tabular}{|c|c|c|c|c|}
\hline Scale name & $N^{\S}$ & Mean & $S D$ & Rank \\
\hline Work values & 1010 & 4.09 & .54 & \\
\hline Terminal values & 1027 & 3.97 & .56 & \\
\hline Self-growth & 1042 & 4.05 & .62 & 5 \\
\hline Self-realization & 1042 & 3.93 & .63 & 6 \\
\hline Self-esteem & 1036 & 3.92 & .56 & 7 \\
\hline Instrumental values & 1026 & 4.18 & .61 & \\
\hline $\begin{array}{l}\text { Social interaction considera- } \\
\text { tions }\end{array}$ & 1046 & 4.29 & .66 & 1 \\
\hline $\begin{array}{l}\text { Security and economic con- } \\
\text { siderations }\end{array}$ & 1036 & 4.18 & .74 & 2 \\
\hline $\begin{array}{l}\text { Stability and freedom from } \\
\text { anxiety considerations }\end{array}$ & 1041 & 4.15 & .67 & 3 \\
\hline $\begin{array}{l}\text { Recreation, health and trans- } \\
\text { port considerations }\end{array}$ & 1044 & 4.09 & .66 & 4 \\
\hline Job involvement & 1041 & 3.37 & .60 & \\
\hline Complete involvement & 1042 & 3.17 & .68 & 2 \\
\hline Strong involvement & 1046 & 3.71 & .62 & 1 \\
\hline Organizational commitment & 1019 & 3.26 & .50 & \\
\hline Values commitment & 1036 & 3.30 & .59 & 2 \\
\hline Effort commitment & 1041 & 3.60 & .59 & 1 \\
\hline Retention commitment & 1035 & 2.99 & .66 & 3 \\
\hline
\end{tabular}

For work values, "instrumental values" were seen as the most important values for the sample. The order of importance based on the mean for "instrumental values" were "social interaction considerations", followed by "security and economic considerations", "stability and freedom from anxiety considerations", and finally "recreation, health and transport considerations". Moderate value was placed on "terminal values", with the order of importance dropping from "self-growth", to "self-realization", down to "selfesteem" (3.92). Thus "instrumental values" were overall very important to the nurses, while "terminal values" were seen as somewhat less important.

Job involvement, the average of $3.37(\mathrm{SD}=.60)$ implies that the nurses are reasonably involved with their jobs and are not very different in their levels of involvement. The rank order of the subscales showed that the strong involvement factor had a mean of 3.71 , but complete involvement was lower with a mean of 3.17. Organizational commitment, the mean for RNs in this study was $3.26(\mathrm{SD}=.50)$, implies that the nurses were equally committed to their hospitals. Respondents scored higher on "effort commitment", with a mean of 3.60, and lower on "retention commitment", with a mean of 2.99 .

\subsection{Work Values and Job Involvement}

In the results of General Linear Model (GLM) uni-variate analysis, as seen in Table 4, unstandardized regression coefficients were obtained by regressing work values on job involvement, indicated that work values contribute significantly to job involvement $(\mathrm{B}=0.2 ; \mathrm{P}<0.001)$. It was highlighted that work values and job involvement are generally regarded as resulting from socialization processes, and the social learning flowing from these processes. Of more importance is the interpretation of partial eta square $(\eta 2)$, an estimate of the magnitude of the relationship between work values and job involvement, controlling for demographics, hospital and organizational commitment. The partial $\eta 2$ result indicates that work values explain only five percent of the variation in job involvement. Work values are less influential than organizational commitment, demographics and the hospital nurses worked at, when explaining job involvement. All the partial $\eta 2$ are small, suggesting that factors other than those assessed in this study may be important in explaining job involvement. The findings suggest that, although the obtained correlations were not strong, to a certain extent each value these employees sought to find in their life or at work were positively related to several specific involvements in their present job. Alternatively, the results could be interpreted such that employees' involvement in their present job was positively related to many values that individuals' hope to find in their various life and work roles. An individual may see a job as important to his or her identity, due to the values placed on social relationships, security or sense of meaningful activity.

Table 4. Estimated Influence of Work Values on Job Involvement after Adjustment for Demographics, Hospital and Organizational Commitment

\begin{tabular}{ccccc}
\hline Independent variables & $N$ & $B^{\dagger}$ & $S E^{\S}$ & Partial Eta $^{2}$ \\
\hline $\begin{array}{c}\text { Organizational com- } \\
\text { mitment }\end{array}$ & 930 & $.48^{* *}$ & .04 & .16 \\
Work values & 930 & $.20^{* *}$ & .03 & .05 \\
\hline \multicolumn{5}{c}{ Note $1: * * p<.01$} \\
Note 2: $\uparrow:$ unstandardized regression coefficient; $\S$ : standard error. \\
\hline
\end{tabular}

\subsection{Work Values and Organizational Commitment}

As shown in Table 5, unstandardized regression coefficients obtained by regressing work values on organizational commitment indicated that work values contribute significantly to organizational commitment $(\mathrm{B}=.08)$. This finding may mean that those nurses who had a higher commitment to their organization also recognized the importance of many values in their various life or work roles. Partial $\eta 2$ indicated that work values explain only one perecnt of the variation in organizational commitment. Work values are less influential 
than job involvement, demographics and hospital in explaining organizational commitment. As in the previous analysis, other factors may be important in explaining organizational commitment, because all the partial $\eta 2$ are small.

Table 5. Estimated Influence of Work Values on Organizational Commitment after Adjustments for Demographics, Hospital and Job Involvement

\begin{tabular}{lcccc}
\hline Independent variables & $N$ & $B^{\dagger}$ & $S E^{\S}$ & Partial Eta $^{2}$ \\
\hline Job involvement & 930 & $.31^{* *}$ & .02 & .16 \\
Work values & 930 & $.08^{* *}$ & .03 & .01 \\
\hline Note $1: * * p<.01$ & & & & \\
Note $2: \uparrow:$ unstandardized regression coefficient; $\S$ : standard error. \\
\hline
\end{tabular}

\subsection{Job Involvement and Organizational Commitment}

As highlighted in Table 6, unstandardized regression coefficients obtained by regressing job involvement on organizational commitment indicated that job involvement contributed significantly to organizational commitment (B $=.31)$. Partial $\eta 2$ indicates that job involvement explain 16 percent of the variation in organizational commitment. Job involvement is more influential than work values, demographics and hospital in explaining organizational commitment. Given the small partial $\eta 2$ values, it is likely that factors other than job involvement, work values, demographics and the hospital variable may be important in explaining organizational commitment. As predicted, there was a positive relationship between job involvement and organizational commitment, which is in line with the literature $(7,19,21,29)$. This finding suggests that individuals who had higher job involvement had more commitment to their organization. According to social exchange theory, individuals bring certain needs and skills to the organization, and expect that the organization will provide an environment in which those needs are satisfied and those skills are used. If individual psychological needs are satisfied, employees will engage themselves more fully and invest greater time and energy on behalf of the organization. Therefore, it seems logical that perceptions of a positive work environment will lead to satisfaction, and less intent to leave the organization. This is consistent with Kanungo's view that high job involvement occurs when the work environment meets the individual's needs.

Table 6. Estimated Influence of Job Involvement on Organizational Commitment after Adjusted for Demographics, Design Effect and Work Values

\begin{tabular}{ccccc}
\hline Independent variables & $\mathrm{N}$ & $\mathrm{B} \dagger$ & $\mathrm{SE} \S$ & Partial Eta2 \\
\hline Work values & 930 & $.08^{* *}$ & .03 & .01 \\
Job involvement & 930 & $.31^{* *}$ & .02 & .16 \\
\hline Note $1: * * \mathrm{p}<.01$ & \\
Note $2: \uparrow:$ unstandardized regression coefficient; $\S$ : standard error.
\end{tabular}

\subsection{Findings in Relation to Mediating Processes}

Previous studies have hypothesized that work values could directly affect job involvement (6). An indirect effect of work values on organizational commitment through job involvement has also been proposed $(9,23)$. SEM was em- ployed in the present study. The initial solution using SEM suggested that the original model was an inadequate fit to the data. Chi-square (X2) for the proposed model was 2,107.25 with 51 degrees of freedom $(\mathrm{p}<.01)$, and the chi-square to degrees of freedom ratio (X2/df) was 41.32. All of the fit indicators were below levels indicative of a good fit (NFI = $0.85, \mathrm{CFI}=0.85, \mathrm{GFI}=0.71$ and $\mathrm{RMSEA}=0.22$, above the accepted value of 0.1 ). Therefore, the model needed to be altered.

In the revised model, one direct path between work values and organizational commitment was dropped. This revised model had led to an improved model with a ratio of chi-square to degrees of freedom of approximately $5: 1$, and a RMSEA of 0.06 , indicating a better moderate fit to the data. The NFI, CFI, and GFI indicators ranged from 0.98 to 0.99 , which also indicated an excellent model fit. Two models were evaluated in terms of their fit to the data and in comparison to each other. The difference between the chi-square fit statistics for the original and revised model was 2,045.21, based on 39 degrees of freedom. The original model was rejected in favor of the revised model, because the fit of original model was significantly worse than that of the revised model. The fit statistics for the original, revised and reverse models and model comparisons described in the following sections are summarized in Table 7 . The results revealed that work values affected organizational commitment only through job involvement, as seen in Figure 2.

Table 7. Model Fit Statistics

\begin{tabular}{cccccccc}
\hline Model & Chi-square & df & X2/df & NFI & CFI & GFI & RMSEA \\
\hline Original & $2,107.25$ & 51 & 41.32 & .85 & .85 & .71 & .22 \\
Revised & 62.04 & 12 & 5.16 & .99 & .99 & .98 & .06 \\
Difference & $2,045.21$ & 39 & & & & & \\
\hline
\end{tabular}

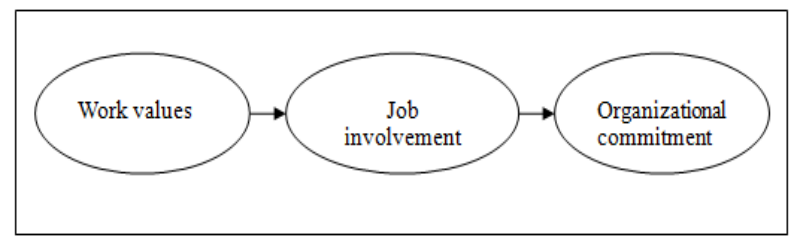

Figure 2. The Revised Model

Further exploration of how job involvement plays an important mediating role between work values and organizational commitment is required. This study is not able to confirm Randall and Cote's predictions regarding the direct effect of work values on organizational commitment, which was lacking in tests of Randall and Cote's two models (both the original and revised models). In Figure 2, however, it can be seen that the current results affirm the basic content of Randall and Cote's revised model, although the direct link between work values and organizational commitment is not clearly drawn. It was anticipated that having strong work values would result in increased job involvement, which would subsequently lead to increased organizational commitment. It could also be the case that employees who are involved in their job have positive work values that they attribute to their organization. 


\section{Discussion}

The current results add to the understanding of work values and their relationships with job involvement and organizational commitment among Taiwanese nurses. Moreover, this study indicates that job involvement mediates the relationship between work values and organizational commitment. The findings of the present study have implications for organizations that are attempting to enhance organizational commitment through increased job involvement. It is anticipated that improving these factors will be associated with reduced turnover and absenteeism and hence the establishment of more effective organizations. A more effective organizational environment, that implements participatory management, recognizes the value of professional nursing practice, and values communication between clinical nurses and leadership, will be conducive to good nursing practice. This research has added to the existing nursing literature, providing key information about links between work values, job involvement, and organizational commitment. This study provides a theoretical and empirical basis for further study of nursing issues in Taiwan, and in other parts of the world.

\subsection{Limitations}

Several limitations of this study were identified considered, where possible. The study used a cross-sectional design, and accordingly cannot establish temporal or causal relationships between independent and dependent variables. Future research should consider alternative methods, such as a longitudinal study among nurses, by measuring the latent variables at various career stages. Another limitation of the study is the proportion of variance in the dependent variables explained by the independent variables. Although significant, these figures are somewhat low (1-16 percent of the variance in dependent variables), suggesting that other variables not included in this study can greatly influence organizational commitment. Therefore, additional variables should be evaluated in future research. The third limitation of this study is the measure of job involvement used. Although Kanungo's (14) JIQ was demonstrated to be a uni- dimensional construct, the present study revealed that job involvement was a two-dimensional construct. Based on this study, researchers should be careful in drawing conclusions about job involvement. The last limitation is the measure of work values implemented. In this study, the WVI might not be a measure of the PWE used in Randall and Cote's (23) study. Therefore, one should be careful about drawing parallels between these concepts. A cross-cultural research comparison would be worthwhile in order to determine if the current findings can be replicated in other populations, and to investigate possible cultural differences.

\section{ACKNOWLEDGEMENTS}

The authors would like to express sincere gratitude to Dr. Diana Battistutta for her kind assistance and specialized knowledge in statistics. We would also like to thank those who gave permission to perform the research in their hospitals.

\section{REFERENCES}

[1] Bartlett SM. A note on the multiplying factors for various Chi Square approximations. Appl Stat 1954; 16 (Series B), 296-298

[2] Bentler PM. Comparative fit indexes in structural models. Psychol Bull 1990; 107(2), 238-246

[3] Bentler PM, Bonett DG. Significance tests and goodness of fit in the analysis of covariance structures. Psychol Bull 1980; $88,588-606$

[4] Blau G.J, Boal KB. Conceptualizing how job involvement and organizational commitment affect turnover and absenteeism. Acad Manage Rev 1987; 12(2), 288-300

[5] Brown D. The role of work and cultural values in occupational choice, satisfaction, and success: A theoretical statement. J Couns Dev 2002; 80(1), 48-56

[6] Brown MW, Cudeck R. Alternative ways of assessing model fit', In K.A. Bollen and J.S. Long (Eds.), Testing structural equation models (136-162). Thousand Oaks, CA: Sage, 1993

[7] Buffardi L, Niebisch KY. Job involvement and organizational commitment: An empirical comparison. Paper presented at the Annual Meeting of American Psychological Association, GA: Atlanta, 1988

[8] Chuang HT. A study on the relationship among work values, professional commitment, job involvement, and intention of changing occupation of the interior design practitioners. $\mathrm{J}$ HRM 2002; 2(2), 1-18

[9] Cohen A. Relationships among five forms of commitment: An empirical assessment. J Organ Behav 1999; 20(3), 285-308

[10] De Vet HCW, Ader HJ, Terwee CB, Pouwer F. Are factor analytical techniques used appropriately in the validation of health status questionnaires? A systematic review on the quality of factor analysis of the SF-36. Qual Life Res 2005; $14,1203-1218$

[11] Hertzog C. Using Confirmatory Factor Analysis for Scale Development and Validation. New York: Baywood, 1988

[12] Huang KR. Research on the relation between teacher's organizational commitment in senior high school and teacher's professional commitment. The National Chengchi University Journal 1986; 53, 55-84

[13] Kaiser H. An index of factorial simplicity. Psychometrika 1974; 39, 31-36

[14] Kanungo RN. Measurement of job and work involvement. J Appl Psychol 1982; 67(3), 341-349

[15] Lee YD, Chung CM. The relationship of corporate culture, employees' work values and organizational commitment: An empirical study of major business groups in Taiwan. Journal of Chang Jung Christian University 2001; 4(2), 1-18 
[16] Mathieu JE, Zajac DM. A review and meta-analysis of the antecedents, correlates, and consequences of organizational commitment. Psychol Bull 1990; 108(2), 171-194

[17] Morrow PC. Concept redundancy in organizational research: The case of work commitment. Acad Manage 1983; 8(3), 486-500

[18] Morrow PC. The Theory and Measurement of Work Commitment. Greenwich, C.T.: JAI, 1993

[19] Morrow PC. \& McElroy, J. C. Work commitment and job satisfaction over three career stages. J Vocat Behav 1987; 30 (3), 330-346

[20] Mowday RT, Porter LW, Steers RM. Employee- organization Linkages - The Psychology of Commitment, Absenteeism, and Turnover. New York: Academic Press, 1982

[21] Mowday RT, Steers RM, Porter LW. The measurement of organizational commitment. J Vocat Behav 1979; 14(2), 224-247

[22] Pallant J. SPSS survival manual, 2nd edition. Sydney: Allen \& Unwin, 2005

[23] Randall DM, Cote JA. Interrelationships of work commitment constructs. Work Occup 1991; 18(2), 194-202

[24] Robbins SP. Organizational Behaviours: Concepts, Controversies, and Application, 6th ed. NJ: Prentice-Hall, Englewood Cliffs, 1993

[25] Segars AH, Grover V. Re-examining perceived ease of use and usefulness: A confirmatory factor. MIS Quarterly $1993 ; 17(4), 517-525$

[26] Shore TH, Thornton GC, Shore LM. Distinctiveness of three work attitudes: Job involvement, organizational commitment, and career salience. Psychol Rep 1990; 67(3), 851-858
[27] Stevens JM, Beyer JM, Trice HM. Assessing personal, role, and organizational predictors of managerial commitment. Acad Manage Rev 1978; 21(3), 380

[28] Super DE. Work Values Inventory. Boston: Houghton Miffin, 1970

[29] Tabachnick BG, Fidell LS. Using multivariate statistics, 4th edition. Allyn and Bacon, Boston, Mass: 2001

[30] Tumulty G., Jernigan IE, Kobut G. Reconceptualising organizational commitment. J Nurs Adm 1995; 25 (1), 61-65

[31] Van Wyk R, Boshoff AB, Owen JH. Construct validity of psychometric instruments developed in the United States, when applied to professional people in South Africa. S African J Economic and manage Sci 1999; 1, 1-72

[32] Wang HJ. Economic order and work ethics: The changes and selections of work ethics that the Chinese face during the transformation. J Social Theory 2000; 3(2), 337-363

[33] Wang YD, Yang C, Wang KY. Comparing the effect of career achievement on job satisfaction, organizational commitment and intent to quit for public and private employees. Chiao Da Manage Rev 2001; 21 (2), 1-25

[34] Wu JJ, Yang QL. A study of individual characteristics, organizational climate and organizational commitment. Cheng Chi University, Taipei, Taiwan, 1982 (Unpublished Master Thesis)

[35] Wu TL, Lin PF. A study on the relationship between job stress and organizational commitment of the teachers in the elementary schools. J Elementary Edu 2003; 15, 193-229

[36] Wu TS, Lee KC, Liu YS, Ou HM. (Eds.) Development of Work Values Inventory. National Youth Commission, Executive Yuan, Taiwan: 1996 